\title{
A Male Case of Synchronous Double Cancers of the Breast and Prostate
}

\author{
Masahiro TAJIKA******, Tomonori TuchIYA*, Mori YasudA*, Yoichiro Ito*, Toshiyuki NaKamuRA*, \\ Kimi Yamauchi**, Hajime Yamauchi**, Yoshinori Nishino***, Shigeru Fujihiro***, \\ Hiroto SHIMA ${ }^{* * * *}$, Hisataka Moriwaki***** and Yasutoshi Muto*****
}

\begin{abstract}
A male case of synchronous double cancers of the breast and prostate is reported. An 84-yearold male was admitted to the hospital complaining of general malaise, anorexia and weight loss. A tumor $3 \mathrm{~cm}$ in diameter was noted in his left breast, which was removed by mastectomy, and was diagnosed as papillotubular carcinoma. An induration of his prostate and elevated prostate specific antigen, $\gamma$-seminoprotein and prostatic acid phosphatase levels were also noted. Needle biopsy of his prostate revealed adenocarcinoma. Among the previous 18 reported cases of this combination of cancers, those with no prior estrogen therapy were very rare, the present case being the third ever reported.
\end{abstract}

(Internal Medicine 33: 31-35, 1994)

Key words: estrogen therapy, prostatic acid phosphatase, orchiectomy, prostate specific antigen

\section{Introduction}

Only 18 cases of primary breast cancer synchronous with primary prostatic cancer have been reported (1-16). Among these, 15 cases developed breast cancer during the treatment of their prostatic cancer with estrogen. Recently, we diagnosed a very rare case of double primary cancers of the breast and prostate, which were not related to estrogen therapy and were detected almost simultaneously.

\section{Case Report}

An 84-year-old male was referred to our hospital on March 25, 1992 because of general malaise and anorexia lasting for about three months. He had lost approximately $10 \mathrm{~kg}$ in the previous six months. He had diabetes mellitus from the age of 60 , and was treated with $7.5 \mathrm{mg} /$ day of glibenclamide. No significant family history of cancer was obtained. On physical examination, an elastic, hard mass $3 \mathrm{~cm}$ in diameter was noted in his left breast. He had first felt this tumor five years earlier and occasionally had experienced a bloody discharge from the nipple. There was no other abnormal finding except for pain upon percussion over his entire back. He had no dysuria.

Table 1 shows the laboratory data on admission. Urine analysis was $4+$ for glucose and \pm for occult blood. Blood biochemical tests showed significantly high LDH and ALP activities (618 IU/l and $864 \mathrm{IU} / \mathrm{l}$, respectively), and the isozyme pattern of ALP was type 3-dominant.

A left mastectomy was performed on March 27, 1992. A histological diagnosis of papillotubular carcinoma was made (Fig. 1), and administration of tamoxifen was started. Although there was no apparent metastatic lesion on plain bone X-ray films, the histological diagnosis, being combined with his back pain and high serum ALP activity, prompted us to order ${ }^{99 \mathrm{~m}} \mathrm{Tc}-$ bone scintigraphy. The examination revealed significant bony uptake, particularly on the skull and pyramid, and was felt to be consistent with wide spread bony metastases (Fig. 2).

Since tamoxifen did not relieve his back pain, we screened another possible origin(s) of bony metastases. Among tumor markers measured at this time, prostate specific antigen (PSA), $\gamma$-seminoprotein and prostatic acid phosphatase (PAP) levels were elevated (67.2, 11.0 and $3.8 \mathrm{ng} / \mathrm{ml}$, respectively). Ultrasonography demonstrated prostatic hypertrophy, and a needle biopsy of the prostate was performed on April 25, giving a histologic diagnosis of adenocarcinoma (Fig. 3). The histologic findings of the prostate cancer appeared quite distinct from those of the breast cancer in terms of cellular size and arrangement, shape of nuclei and nucleoli, and chromatin patterns.

From the Departments of *Internal Medicine, **Surgery, ***Urology and ****Pathology, Gifu Red Cross Hospital, Gifu and *****the First Department of Internal Medicine, Gifu University School of Medicine, Gifu

Received for publication June 10, 1993; Accepted for publication November 18, 1993

Reprint requests should be addressed to Dr. Yasutoshi Muto, The First Department of Internal Medicine, Gifu University School of Medicine, 40 Tsukasa-machi, Gifu 500 
TAJIKA et al

Table 1. Laboratory Data on Admission

\begin{tabular}{|c|c|c|c|}
\hline Urinalysis & & $\mathrm{Na}$ & $140 \mathrm{mEq} / \mathrm{l}$ \\
\hline Protein & $(-)$ & $\mathrm{K}$ & $4.0 \mathrm{mEq} / \mathrm{l}$ \\
\hline Glucose & $(4+)$ & $\mathrm{Cl}$ & $103 \mathrm{mEq} / \mathrm{l}$ \\
\hline \multirow[t]{2}{*}{ Occult blood } & $( \pm)$ & $\mathrm{Ca}$ & $8.6 \mathrm{mg} / \mathrm{dl}$ \\
\hline & & $\mathrm{Ca}^{2+}$ & $2.40 \mathrm{mEq} / \mathrm{l}$ \\
\hline \multirow[t]{2}{*}{ Feces Occult blood } & $(-)$ & $\mathrm{P}$ & $1.6 \mathrm{mg} / \mathrm{dl}$ \\
\hline & & $\overline{\text { FBS }}$ & $154 \mathrm{mg} / \mathrm{dl}$ \\
\hline \multicolumn{2}{|l|}{ Peripheral blood } & HbA1c & $7.4 \%$ \\
\hline $\mathrm{RBC}$ & $418 \times 10^{4} / \mathrm{mm}^{3}$ & & \\
\hline \multirow[t]{2}{*}{ WBC } & $7,500 / \mathrm{mm}^{3}$ & CRP & $4.88 \mathrm{mg} / \mathrm{dl}$ \\
\hline & ogram normal) & ESR & $98 \mathrm{~mm} / \mathrm{hr}$ \\
\hline $\mathrm{Hb}$ & $11.9 \mathrm{~g} / \mathrm{dl}$ & & \\
\hline$\overline{\mathrm{Ht}}$ & $36.3 \%$ & Tumor markers & \\
\hline Platelets & $26.1 \times 10^{4} / \mathrm{mm}^{3}$ & CEA & $\begin{array}{r}6.4 \mathrm{ng} / \mathrm{ml} \\
(\mathrm{Normal}<8)\end{array}$ \\
\hline \multicolumn{2}{|l|}{ Blood chemistry } & CA15-3 & $<25 \mathrm{U} / \mathrm{ml}$ \\
\hline T.P. & $6.9 \mathrm{~g} / \mathrm{dl}$ & PSA & $67.2 \mathrm{ng} / \mathrm{ml}$ \\
\hline Albumin & $3.6 \mathrm{~g} / \mathrm{dl}$ & & $(<3.6)$ \\
\hline T.Bil. & $0.6 \mathrm{mg} / \mathrm{dl}$ & $\gamma$-seminoprotein & $11 \mathrm{ng} / \mathrm{ml}$ \\
\hline GOT & $50 \mathrm{IU} / \mathrm{l}$ & & $(<4.0)$ \\
\hline$\overline{\text { GPT }}$ & $28 \mathrm{IU} / 1$ & PAP & $3.8 \mathrm{ng} / \mathrm{ml}$ \\
\hline $\mathrm{LDH}$ & $618 \mathrm{IU} / 1$ & & $(<3.0)$ \\
\hline$\gamma \mathrm{GTP}$ & $0.41 \mathrm{IU} / 1$ & & \\
\hline ALP & $864 \mathrm{IU} / \mathrm{I}$ & & \\
\hline \multicolumn{2}{|c|}{ (isozyme ALP-3 dominant) } & & \\
\hline Ch-E & $0.32 \Delta \mathrm{PH}$ & & \\
\hline BUN & $18.0 \mathrm{mg} / \mathrm{dl}$ & & \\
\hline Creatinine & $0.8 \mathrm{mg} / \mathrm{dl}$ & & \\
\hline Amylase & $50 \mathrm{IU} / 1$ & & \\
\hline
\end{tabular}
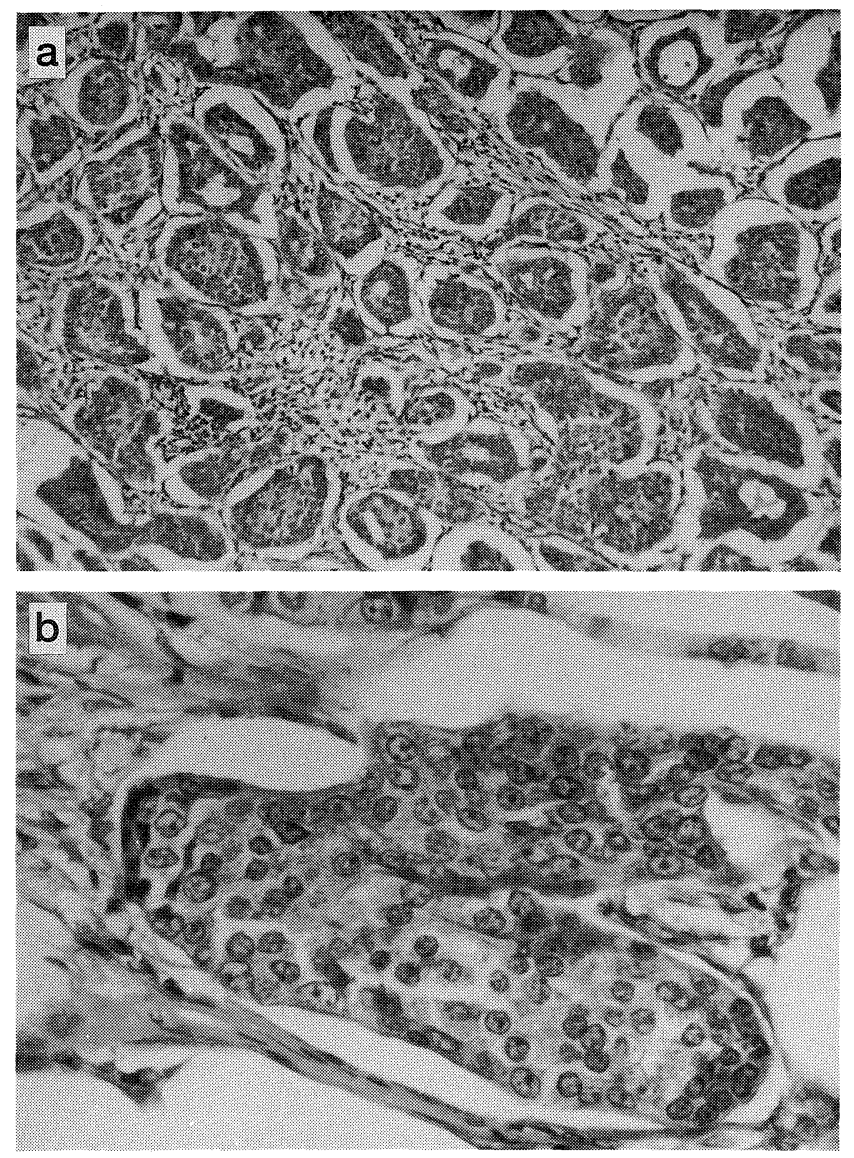
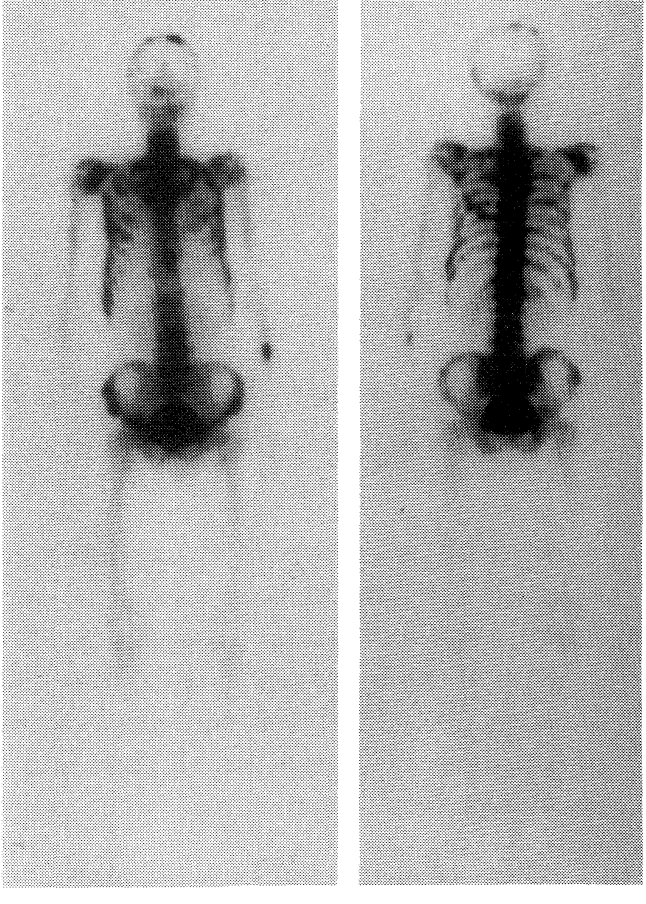

\section{$\mathrm{R}$ Anterior L L Posterior $\mathrm{R}$ \\ 92. 3.28}

Fig. 2. $\quad{ }^{99 \mathrm{~m}} \mathrm{Tc}$-bone scintigraphy on March 28,1992 shows intense uptake over the entire body, particularly on the skull and pyramid.

Immunohistochemical staining of the breast cancer was negative for PSA and PAP. Therefore, this case was diagnosed as synchronous double cancers of the breast and prostate. Tamoxifen was withdrawn due to its ineffectiveness on bony metastases, and an orchiectomy was performed on May 11.

Two days before orchiectomy, the patient suddenly developed dyspnea and a pleural effusion was observed bilaterally (Fig. 4). The pleural fluid was exudative, suggesting carcinomatous pleuritis, although the cytology was negative. As shown in Fig. 5, following orchiectomy, the patient's dyspnea and pleural effusion improved, his ALP and LDH levels decreased somewhat, his back pain improved, and the levels of the tumor markers decreased. The patient was discharged on June 5, 1992, and has had follow-up visits in our outpatient clinic. He has felt well up until his last visit in September 1993.

\section{Discussion}

As mentioned above, there have been only 18 reported cases (including this case) of double cancers of the breast and prostate

Fig. 1. Histologic findings of the breast cancer. a) Glandular formation is predominant while aggregated cancer cells are also observed in some parts (HE stain, $\times 100$ ). b) Cancer cells show anisocytosis and almost round nuclei with clear nucleoli. The chromatin pattern in nuclei is rough (HE stain, $\times 200$ ). 


\section{Male with Breast and Prostate Cancers}
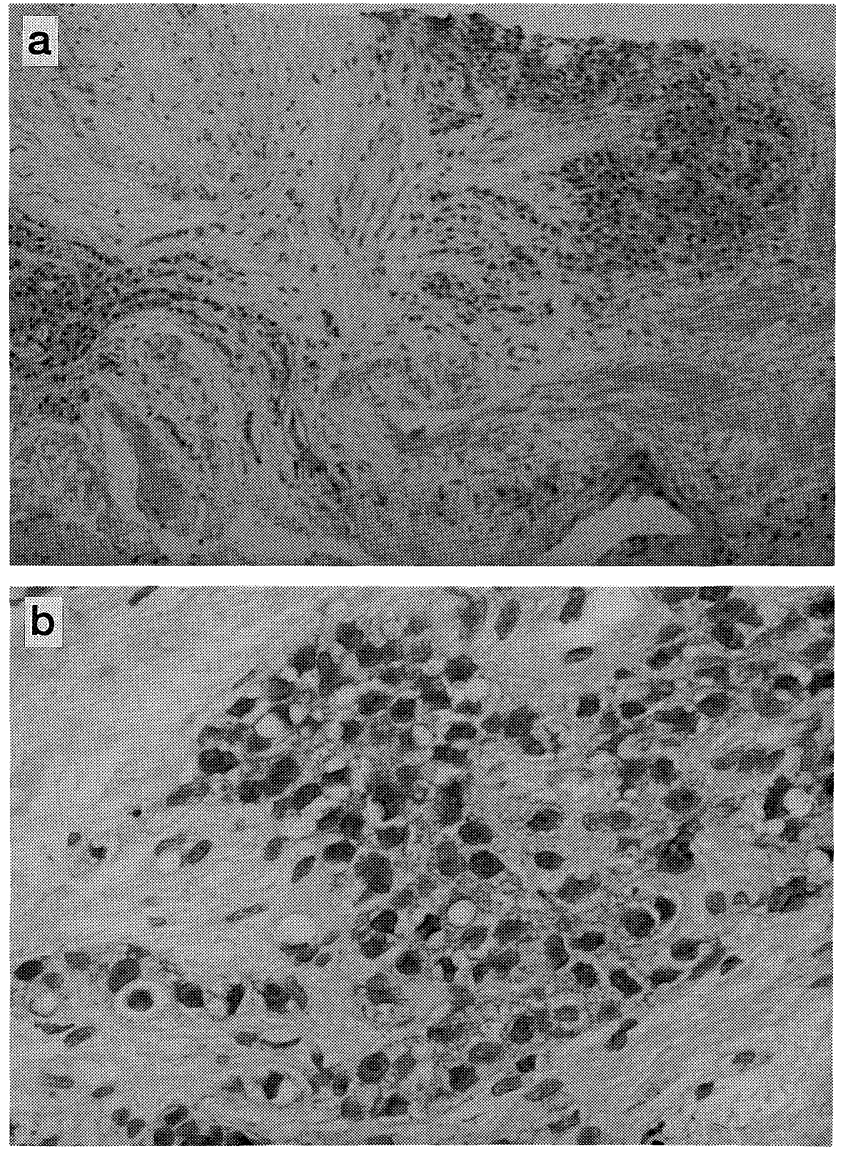

Fig. 3. Histologic findings of the prostate cancer obtained by needle biopsy. a) Small cells are predominant. Trabecular formation is frequently observed, and tubular structures are also found in some parts (HE stain, $\times 100$ ). b) Nuclei are irregular in shape, and nucleoli stand out. When compared to the histological pictures of the breast cancer, the chromatin pattern of each nucleus appears uneven (HE stain, $\times 200$ ).
(Table 2). Cases which are not related to prior estrogen therapy are very unusual, the present patient being the third such case reported. In this case, the diagnosis of the primary prostate cancer was based on both the histologic characteristics and the elevated tumor markers such as PSA, $\gamma$-seminoprotein and PAP. The patient's clinical course after orchiectomy seems to
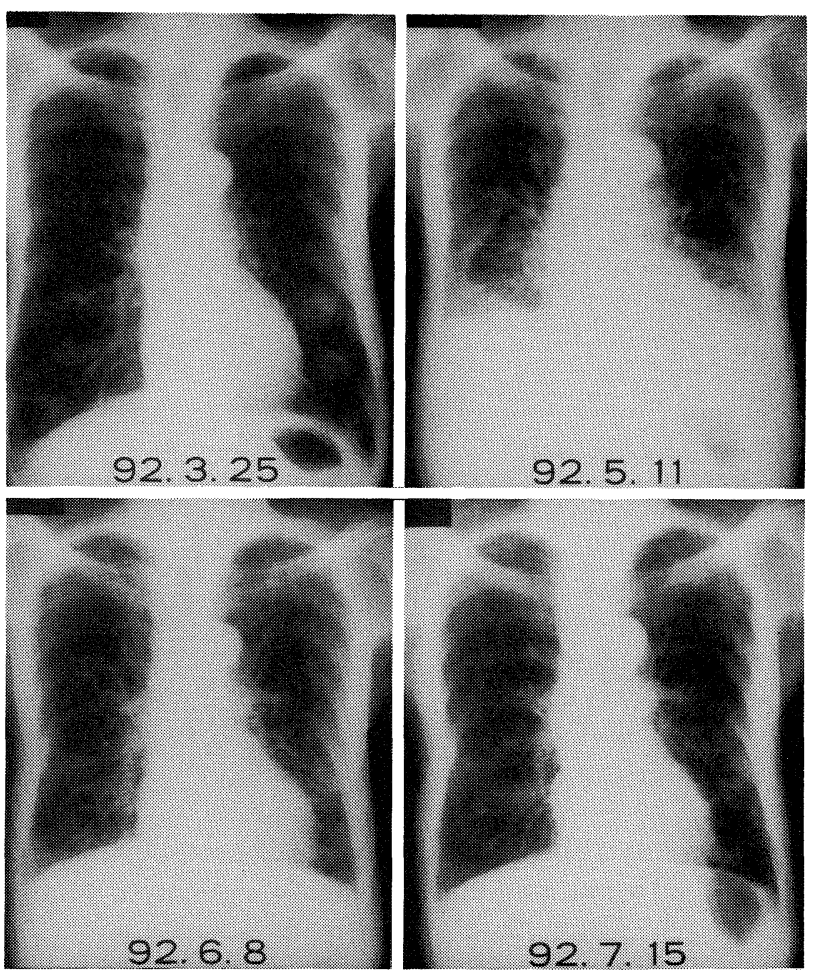

Fig. 4. Time course of changes in the chest $\mathrm{X}$-ray examinations.

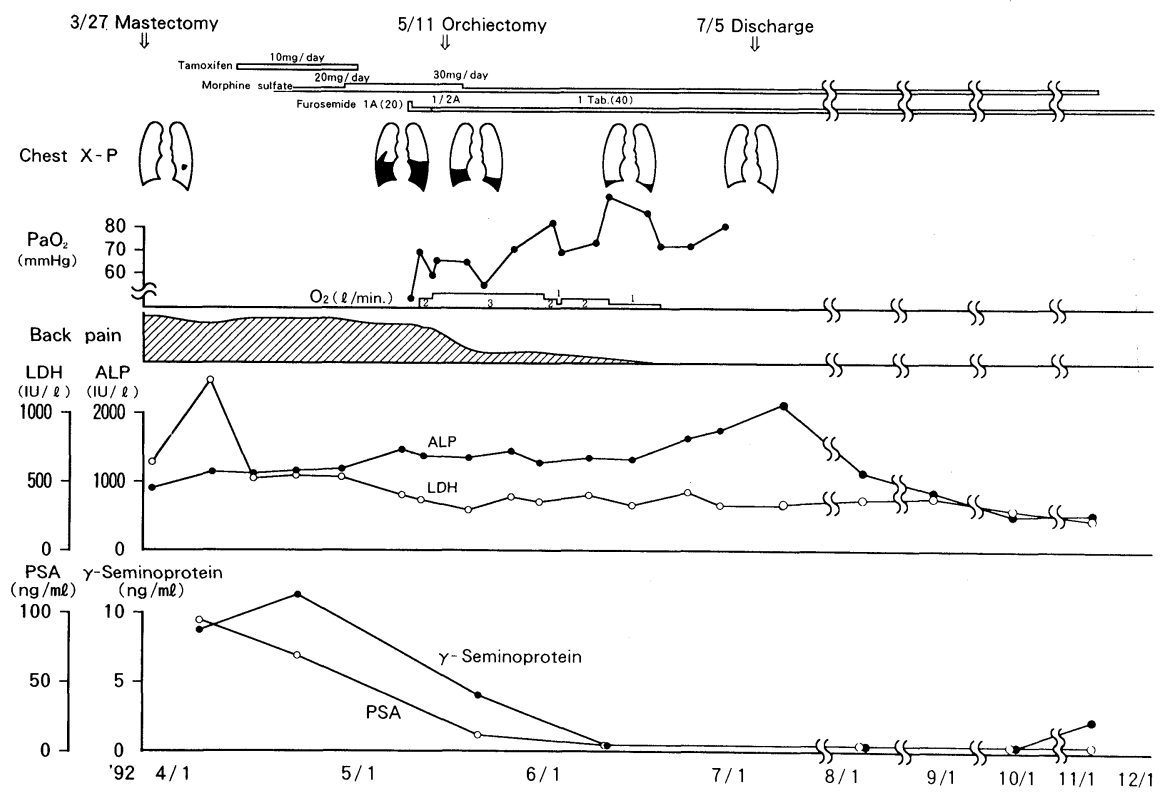

Fig. 5. Clinical course of the patient. PSA: prostate specific antigen. 
Table 2. Reported Male Cases of Double Cancers of the Prostate and Breast

\begin{tabular}{|c|c|c|c|c|}
\hline Authors & Year & No. of case & Age & Estrogen therapy \\
\hline Darget R & 1946 & 1 & $\mathrm{NR}^{* 3}$ & $(+)$ \\
\hline Grandni GF & 1948 & 1 & 60 & $(+)$ \\
\hline Abramson W & 1948 & 1 & 51 & $(+)$ \\
\hline Reimann-Hunziker G & 1948 & 1 & 68 & $(+)$ \\
\hline Howard RF & 1949 & 1 & 71 & $(+)$ \\
\hline Claisse R & 1951 & 1 & NR & $(+)$ \\
\hline McClure JA ${ }^{* 1}$ & 1951 & 1 & NR & $(+)$ \\
\hline Gibba A & 1952 & 1 & NR & $(+)$ \\
\hline Graves GY & 1952 & 1 & 78 & $(+)$ \\
\hline Jakobsen AHI & 1952 & 1 & 70 & $(+)$ \\
\hline Gwynne JF & 1957 & 1 & 53 & $(+)$ \\
\hline O'Grady WP & 1969 & 1 & 77 & $(+)$ \\
\hline Wilson SE & 1976 & 1 & 75 & $(+)$ \\
\hline Sobin $\mathrm{LH}^{* 2}$ & 1980 & 1 & NR & $(+)$ \\
\hline Choudhury M & 1982 & 1 & 65 & $(+)$ \\
\hline Sobin $\mathrm{LH}^{* 2}$ & 1980 & 1 & NR & $(-)$ \\
\hline Moldowin RM & 1989 & 1 & 74 & $(-)$ \\
\hline Tajika M (present case) & 1992 & 1 & 84 & $(-)$ \\
\hline
\end{tabular}

Total

18

$15 / 18(83.3 \%)$

${ }^{* 1}$ Among 17,000 patients on estrogen therapy for prostatic carcinoma. ${ }^{* 2}$ Among 7,000 patients with prostatic carcinoma from the Birmingham (UK) Cancer Registry. ${ }^{* 3}$ NR: not reported.

suggest that the prostate cancer was responsible for his pleuritis and multiple bone lesions. The breast tumor was strongly suspected as being a primary lesion because its histologic findings were distinct from those of the prostate cancer. In addition, immunohistochemistry of the breast tumor for PSA and PAP, performed to rule out a metastasis of prostate cancer (17), was negative. Elevated blood PSA and PAP levels and negative staining of the breast tumor tissue for PSA and PAP may further confirm that the breast cancer is also a primary one.

It is not clear what the common underlying mechanism of carcinogenesis is in the present patient with synchronous primary breast and prostate cancers, the former being estrogendependent and the latter testosterone-dependent. The most proclaimed hypothesis for the common mechanism underlying the onset of double cancers of this type is the administration of estrogen, which induces gynecomastia and may provide a fertile environment for the development of mammary carcinogenesis $(14,16)$. In fact, as shown in Table 2,15 of the 18 reported cases of these double cancers had received estrogen treatment for their prostate cancer at the time of the diagnosis of the breast cancer. However, this hypothesis itself is still controversial $(7,20,21)$ and in any event is not applicable to the present case.

On the other hand, it is well known that the incidence of multiple cancers rises with age (18). Although the prevalence rate of prostate cancer is not available in Japan, the corrected mortality rate in Japan in 1990 is estimated to be $5.7 / 100,000$ for prostate cancer and $0.1 / 100,000$ for male breast cancer (19). By simply multiplying these two incidences, one can roughly estimate the rate of the double cancers to be as rare as 0.6 over ten billion. However, prostate cancer is known to be associated with an incidence of multiple cancers as high as $11.7 \%$ (20) or $13 \%$ (21). The characteristic age distribution of prostate cancer patients (older than 70 or 75 years) is postulated to be responsible for such a high incidence of multiple cancers. The actual incidence of breast cancer among prostate cancer patients who did not receive estrogen therapy has been reported to be $1 / 7,000$ in United Kingdom by the Birmingham Cancer Registry (14) and $1 / 7,000$ in the United States by the Connecticut Cancer Registry (22). This incidence is not known in Japan, but the present case seems to be the first one reported in Japan.

As to the possible role of underlying diabetes mellitus and its therapeutics, diabetes mellitus is known to occasionally reduce testosterone and androgen levels (23), and may thus promote the development of mammary carcinogenesis. However, the actual incidence of breast and prostate cancers in patients with diabetes mellitus is not higher than in patients without diabetes mellitus (24). Chronic toxicity testing of glibenclamide, which was used in this patient to treat his diabetes mellitus, has not revealed any mutagenic side effect (25).

Taken together, the age-related rise in the incidence of multiple primary cancers, particularly in prostate cancer patients, seems to be the factor most likely responsible for the double cancers of the present case.

As to the treatment of male primary breast cancer, mastectomy and endocrine therapy with tamoxifen are the treatments of choice (16). Tamoxifen has been presumed to be effective against male breast cancer, based on the finding that the estrogen receptor positive rate is as high as $89.5 \%$ in male breast cancer (26). However, the efficacy of this drug on prostatic cancer has been questioned by some investigators. Glick et al (27) have reported that the partial response rate and disease stabilization rate in a phase II trial of tamoxifen were as low as 7 and 20\%, respectively, for patients with metastatic prostate cancer.

Administration of LH-RH antagonist is regarded to be the first choice among endocrinologic treatments for prostate cancer, but the agent may raise the estrogen level transiently and induce gynecomasthia in approximately $2 \%$ of patients who receive the drug (phase III clinical trial data from ICI Pharma Co., Ltd. Osaka, Japan). Although we did not know what definite effect this possible transient surge of estrogen may excert on his breast cancer, we favored orchiectomy which removes the major source of both testosterone and estrogen in males. Thus, the present patient underwent both mastectomy and orchiectomy. The significant improvement observed in his clinical course after the operations support our management of this patient.

\section{References}

1) Darget R. Epithelioma bilateral de la glande mammaire a la suite de l'emploi prolong d'un oestrogene de syntheses deus le traot, emt d'un cancer prostatique. Assoc Franc d'Urol, Proc-Verb 40: 405, 1946 (in French).

2) Grandni GF. Ginecomastia con degenerazione cancerigener in prostatico doppo trattamento estrogens. Oncologica 1: 129, 1948 (in Italian). 


\section{Male with Breast and Prostate Cancers}

3) Abramson W, Warshawsky H. Cancer of breast in male secondary to estrogenic administration. J Urol 59: 76, 1948.

4) Reimann-Hunziker G. Brustdrusenkarzinam nach ovocyclinbehandlung eines prostatakarzinams. Hebut Chir Acta 15: 242, 1948.

5) Howard RF, Grosjean WA. Bilateral mammary carcinoma in males coincident with prolonged stilbestrol therapy. Surgery 25: 300, 1949.

6) Claisse R, Daymus L. Tumeur mammaire d'evolution rapide, au cours du traitement d'un cancer de la prostate par les oestrogenens de Sinehtse. Bull Mem Soc Med Hop Paris 67: 1137, 1951 (in French).

7) McClure JA, Higgins CC. Bilateral carcinoma of male breast after estrogen therapy. JAMA 146: 7, 1951.

8) Gibba A. Carcinoma mammario bilateral comporisi in corso di terapia estrogen a per cancro prostatica. Urologia 19: 180, 1952 (in Italian).

9) Graves GY, Harris HS. Carcinoma of the male breast with axillary metastases following stilbestrol therapy. Ann Surg 135: 411, 1952.

10) Jakobsen AHI. Bilateral mammary carcinoma in male following stilbestrol therapy. Acta Pathol Microbiol Scand 31: 61, 1952.

11) Gwynne JF, Dawson. EO. Carcinoma of the breast in a male with carcinoma of the prostate. Anst N Z J Surg 26: 235, 1957.

12) O'Grady WP, McDivitt RW. Breast cancer in a man treated with diethylstilbestrol. Arch Pathol 88: 162, 1969.

13) Wilson SE, Hutchinson WB. Breast masses in males with carcinoma of prostate. J Surg Oncol 8: 105, 1976.

14) Sobin LH, Sherif M. Relation between male breast cancer and prostate cancer. Br J Cancer 42: 787, 1980.

15) Choudhury M, De Rosas J, Papsidero L, Wajsman Z, Beckley S, Pontes JE. Metastatic prostatic carcinoma to the breast or primary breast carcinoma? Urology 19: 297, 1982.
16) Moldowin RM, OrihuelaE. Breast masses associated with adenocarcinoma of the prostate. Cancer 63: 2229, 1989.

17) Gotoh A, Matsuura K, Yoshimune S, Takano Y. Immunohistochemical diagnosis of a case of metastatic prostate cancer to breast. Jpn J Urol 80: $1828,1989$.

18) Nakamura $\mathrm{K}$, Aizawa M. Investigation of double cancer with special reference to the combination. Jpn J Cancer Clin 18: 662, 1972.

19) Japan Health and Welfare Statistics Association. J Health Welfare Stat 39 (Suppl No 9): 420, 1992.

20) Williams MJ. Gynecomastia - its incidence, recognition and characterization in 447 autopsy cases. Am J Med 34: 103, 1963.

21) Karsner HT. Gynecomastia. Am J Pathol 22: 235, 1946.

22) Schoenenberg BS. Multiple primary malignancies: The Connecticut experience. Recent Results Cancer Res 58: 99, 1977.

23) Murray FT, Wyss HU, Thomas RG, et al. Gonadal dysfunction in diabetic men with organic impotence. J Clin Endocrinol Metab 65: 127, 1988.

24) Kikuchi H, Hori S, Abe R. Cause of death in diabetics in Japan. Nippon Rinsho 48 (Suppl): 238, 1990.

25) Mizukami K, Yajima R, Komine S, et al. Prolonged toxicity of N-[4(beta-12-methoxy-5-chrolobenzamidol-ethyl)-benzosulfonyl]-N'cyclohexylurea. Pharmacometrics 4: 253, 1970.

26) Iino $Y$, Endo $K$, Izuo M, et al. Endocrine therapy and estrogen receptor in advanced male breast cancer. Hormone and Clinic 29: 925, 1981 (in Japanese).

27) Glick JH, Wein A, Padavic K, Negendank W, Harris D, Brodovsky H. Phase II trial of tamoxifen in metastatic carcinoma of the prostate. Cancer 49: $1367,1982$. 